\title{
Children Safety Devices in Brazil-Why Do People Don't Use Them after the Law?
}

\author{
S. C. V. Abib'1, A. M. Françóia², F. Ricci², M. V. B. Cezillo', B. R. Müller1 \\ ${ }^{1}$ Department of Surgery, Paulista School of Medicine, Federal University of São Paulo, São Paulo, Brazil \\ ${ }^{2}$ Criança Segura-Safe Kids Brazil, São Paulo, Brazil \\ Email: simoneabib@uol.com.br, alessandra@criancasegura.org.br, comunicacao@criancasegura.org.br, \\ marcusv3@hotmail.com, brm001@hotmail.com
}

Received 24 March 2014; revised 21 April 2014; accepted 16 May 2014

Copyright (C) 2014 by authors and Scientific Research Publishing Inc.

This work is licensed under the Creative Commons Attribution International License (CC BY).

http://creativecommons.org/licenses/by/4.0/

(c) (i) Open Access

\section{Abstract}

Introduction: Children safety car devices decrease injuries and death in children. A survey conducted in Brazil in 2009 revealed that only $36.1 \%$ of children safely transported. In 2010, a Brazilian law was implemented, obligating the use of safety devices. The aim of this study is to evaluate the use of such devices after the law and the eventual reasons for non-use. Methods: A significant sample of Brazilian population aged 18 years or more, which normally carry children until 10 years old answered a survey between August 16 and 25, 2012. The study was conducted in two phases. The first one aimed to raise the proportion and profile of the target population, while the second investigated the children car safety device use (or not). Results: 622 interviews. Children's transporters are young males (57\%), living in a metropolitan area in the South region, concerned about safety and law supervision, with greater education level and income than non-transporters $(31 \%)$ who are male with lack of information, living in a non-metropolitan area of the Northeast region that would be motivated to use the device by effective law fiscalization or threat of an accident. Conclusion: Two years after the law it is observed that education, income, age, gender and region of origin influence the use/non-use of the safety seats in Brazil. The accident threat and fiscalization are the main reasons for using the device, showing that the lack of information impairs the democratization of its use and the prevention culture has to be enhanced in the country.

\section{Keywords}

Child Restraint Systems, Wounds and Injuries, Accidents, Traffic, Pediatrics

\section{Introduction}

Criança Segura-Safe Kids Brazil [1] is a non-governmental organization that is a member of Safe Kids 
Worldwide, which is the first and only international organization that exclusively cares for children injury prevention and is present in 22 countries around the world. Our mission is to prevent accidental death and injury to children aged 14 and under and the goal is to reduce $25 \%$ of children deaths in Brazil until 2015. We have already reached a 29\% decrease in children deaths in 2012.

Criança Segura-Safe Kids Brazil empowers families and communities to conduct research, educate adults and children, create safe environments and advocate for effective laws in order to prevent childhood injuries and death. Our strategy is based on communication, mobilization and public policy, working together with the Brazilian Government, private sectors, other NGOs, WHO and universities.

Trauma is the leading cause of children deaths in Brazil (4700 deaths and 125,000 hospitalizations under 14 years of age each year) and traffic accounts for $41 \%$ of mortality. One of the greatest achievements of Criança Segura-Safe Kids Brazil is the implementation of the law that obligates children under 10 years of age to be safely transported in proper devices [2].

The child safety seats for cars significantly reduce the risk of injury in children after motor vehicles collisions [3]-[7]. A recent study in Canada showed that $96.8 \%$ of parents surveyed considered the use of this security device as very important [8].

A survey conducted in Brazil in 2009 revealed that only 36.1\% of children were in safety seats [9] and 42.7\% of them were using the device erroneously [10]. Similar results were found by Criança Segura—Safe Kids Brazil [11].

The mandatory use of child restraint devices in automobiles has been a reality in several countries since the 1980s [12]. In Brazil, the Resolution 277/08 of the National Traffic Council (CONTRAN) [13] was implemented in September 2010, which regulated the use of the device in the country as well as the criteria for its use according to the child's age [13]. Two years after the law implementation that obligated the use of child safety seats in Brazil, this study was performed to evaluate the use of such devices and better understand the eventual reasons for non-use.

\section{Objective}

To evaluate the use of children safety devices in Brazil after the law, the eventual reasons for non-use and the profile of users and non-users.

\section{Methods}

\subsection{Technique}

Quantitative research, with a personal approach, in the points of population flow, through of a structured questionnaire. The check was personal (in situ) and also by phone (after the data collection), covering at least $20 \%$ of the material of each researcher.

\subsection{Universe}

Men and women aged 18 years or more, which normally carry children aged until 10 years old in a car.

\subsection{Place and Date}

The survey was conducted between August 16 and 25, 2012 in Brazil.

\subsection{Sample Design}

The study was conducted in two phases. The first one aimed to raise the proportion and profile of the target population (filter questions), while the second investigated the habits of usage of car safety seat for children (complete questionnaire).

The sample design is representative of the total population aged 18 years or more, based on official information from the 2010 Census (Source: IBGE) [14] and includes the following stages:

-Stratification by Federal Unit and size of each city;

- City randomization; 
-Point of research randomization.

Sample and margin of error:

The sample was divided into 165 municipalities, by region of the country, in two phases (Table 1).

The maximum margin of error plus or minus, considering a confidence interval of $95 \%$ is:

-3915 interviews - 2 percentage points;

-622 interviews -4 percentage points.

Weighing: To ensure the representativeness of the universe, weighing was done by geographic regions, type of municipality and economic classification.

622 respondents carry children until 10 years old in the car, with a total of 968 children transported (Table 2).

Margin of error: the entire sample has an associated error (margin of error). Weighing: the results should be weighted according to the Universe. The weighting is to create a "weight" to each questionnaire in order to equalize the distribution of sample with distribution of universe. If the sample is proportional to the universe this weight is 1 (no need for weighting).

In order to determine the profile, the following variables were analyzed characterizing the Transporters/NonTransporters Stratification Profile: Economic: Economic Active Population or Non-Economic Active Population (EAP or Non-EAP); Monthly Income: Up to 3 Minimum Wage (MW), 3 - 5 MW, 5 - 10 MW, >10 MW. (Minimum Wage in $2012=\mathrm{R} \$ 622,00=\mathrm{US} \$ 3079$ —Exchange rate on 16/08/2012, R\$1 = US\$2,02); Economic Classification: (A, B, C, D and E) adapted from ABEP-Brazilian Association of Research Companies, 2012 [15] (Table 3); Scholarity: Fundamental, Medium and Superior; Geographic Region: North/Midwest, South, Southeast and Northeast; Nature of municipality: Metropolitan Area or Non-Metropolitan Area; Gender: Male and Female; Age: 18 - 24 years, 25 - 34 years, 35 - 44 years, $>45$ years.

\section{Results}

\subsection{Demographic and Economic Profile of Transporters}

Results showed that $12 \%$ of the Brazilian adult population transport children up to 10 years old in cars, corresponding to 1.5 children ratio transported in cars. In this group, the majority uses the car safety seats (57\%), however, above $31 \%$ don't use this device.

\begin{tabular}{ccccc} 
Table 1. Sample distribution. & \multicolumn{3}{c}{} \\
\hline \multirow{2}{*}{ Region of the country } & \multicolumn{2}{c}{ Phase 1 Population over 18 } & \multicolumn{2}{c}{ Phase 2 Target population ${ }^{\mathrm{a}}$} \\
\cline { 2 - 5 } & Absolute & $\%$ & Absolute & $\%$ \\
\hline Southeast & 1638 & 42 & 285 & 47 \\
Northeast & 1134 & 29 & 126 & 18 \\
North/Midwest & 606 & 15 & 100 & 14 \\
South & 537 & 14 & 111 & 21 \\
Total & $\mathbf{3 9 1 5}$ & $\mathbf{1 0 0}$ & $\mathbf{6 2 2}$ & $\mathbf{1 0 0}$ \\
\hline
\end{tabular}

a: Target population = Population with 18 years or over, that carries children in car.

Table 2. Children sample.

\begin{tabular}{|c|c|c|}
\hline \multirow{2}{*}{$\begin{array}{l}\text { Children transported in } \\
\text { car safety seat }\end{array}$} & \multicolumn{2}{|c|}{ Sample } \\
\hline & Absolute & Margin of error ${ }^{a}$ \\
\hline Yes & 604 & $4 \%$ p. \\
\hline No & 364 & $5 \%$ p. \\
\hline Total & 968 & $3 \%$ p. \\
\hline
\end{tabular}

a: Maximum margin of error plus or minus (in percentage points), considering a confidence interval of $95 \%$. 
Transporters/Non-Transporters Stratification Profile is represented in Table 4 and Table 5. In General Population Group and in the Transporters Group 5\% persons refused to answer, in Non-Transporters Group 1\% refused to answer the question Transporters Stratification Profile.

The general profile of children transporters is people with a mean level of education higher than Brazilian population and, with a better economic status and familiar income (Table 6).

\subsection{Distribution by Geographic Region}

The general profile of children transporters, when compared with non-children transporters, is people living in big cities, with a better familiar income and economic status, and with a higher mean level of schooling (Table 7).

Children transported in cars are balanced in gender distribution and most (67\%) are up to 5 years. The non-

Table 3. Economic classification adapted from ABEP-Brazilian Association of Research Companies, 2012 [15]. Data based on 2010 socioeconomic surveyIBOPE [14].

\begin{tabular}{cc}
\hline Class & Average family income gross amount in Reais $(\mathrm{R} \$)^{\mathrm{a}}$ \\
\hline A & 10672 \\
B & 3491 \\
C & 1282 \\
D & 714 \\
E & 477 \\
\hline
\end{tabular}

a: Exchange rate on 16/08/2012 (R\$1 = US\$2,02).

Table 4. Transporters/non-transporters stratification profile by Economic Active Population (EAP), monthly income ${ }^{\mathrm{a}}$, economic classification ${ }^{\mathrm{b}}$ and scholarity in percentage.

\begin{tabular}{|c|c|c|c|c|}
\hline & & Transporter & Non-transporter & General population \\
\hline \multirow{2}{*}{ Occupation } & EAP & 85 & 85 & 70 \\
\hline & Non-EAP & 15 & 15 & 30 \\
\hline \multirow{4}{*}{ Monthly Income ${ }^{a}$} & Up to $3 \mathrm{MW}$ & 31 & 41 & 61 \\
\hline & From 3 to $5 \mathrm{MW}$ & 30 & 34 & 19 \\
\hline & From 5 to $10 \mathrm{MW}$ & 21 & 17 & 10 \\
\hline & More than $10 \mathrm{MW}$ & 13 & 7 & 5 \\
\hline \multirow{4}{*}{$\begin{array}{c}\text { Economic } \\
\text { Classification }^{\mathrm{b}}\end{array}$} & A & 7 & 3 & 3 \\
\hline & B & 55 & 43 & 25 \\
\hline & $\mathrm{C}$ & 36 & 50 & 50 \\
\hline & $\mathrm{D}$ & 2 & 4 & 20 \\
\hline \multirow{3}{*}{ Scholarity } & Fundamental & 29 & 39 & 48 \\
\hline & Medium & 47 & 45 & 39 \\
\hline & Superior & 47 & 45 & 39 \\
\hline \multicolumn{2}{|c|}{ Total } & 604 & 364 & 968 \\
\hline
\end{tabular}

a: Minimum Wage (MW) in $2012=\mathrm{R} \$ 622,00=\mathrm{US} \$ 307,9-E x c h a n g e$ rate on 16/08/2012 (R\$1 = US\$2,02). b: Economic Classification: Criteria Brazil of Economic Classification from ABEP-Brazilian Association of Research Companies, 2012 [15] (Table 3). Data based on 2011 socioeconomic survey—IBOPE (Brazilian Institute of Public Opinion and Statistics) [16]. 
Table 5. Transporters/Non-transporters stratification profile by geographic region, nature of the municipality, gender and age in percentage.

\begin{tabular}{|c|c|c|c|c|}
\hline & & Transporter & Non-transporter & General population \\
\hline \multirow{4}{*}{ Geographic region } & Southeast & 47 & 43 & 43 \\
\hline & Northeast & 18 & 25 & 28 \\
\hline & North/Midwest & 15 & 18 & 15 \\
\hline & South & 20 & 14 & 14 \\
\hline \multirow{2}{*}{$\begin{array}{l}\text { Nature of the } \\
\text { municipality }\end{array}$} & Metropolitan area & 41 & 31 & 39 \\
\hline & Non-metropolitan area & 59 & 69 & 61 \\
\hline \multirow{2}{*}{ Gender } & Male & 71 & 77 & 48 \\
\hline & Female & 29 & 23 & 52 \\
\hline \multirow{4}{*}{ Age } & 18 - 24 years & 14 & 9 & 16 \\
\hline & 25 - 34 years & 32 & 27 & 25 \\
\hline & 35 - 44 years & 30 & 38 & 20 \\
\hline & 45 years or older & 24 & 27 & 39 \\
\hline \multicolumn{2}{|r|}{ Total } & 604 & 364 & 968 \\
\hline
\end{tabular}

Table 6. Comparison between children transporters and general Brazilian population.

\begin{tabular}{ccc}
\hline & Brazilian population (18 years or more) & Children transporter \\
\hline Mean age & 41 years old & 38 years old \\
Mean level of schooling & $48 \%$ (Basic education) & $24 \%$ (Superior education) \\
Economic level ${ }^{\mathrm{a}}$ & Class C (50\%) & Class B (55\%) \\
Familiar Income (US\$) & about 1000 & about 2000 \\
\hline
\end{tabular}

a: Economic Classification: Criteria Brazil of Economic Classification from ABEP-Brazilian Association of Research Companies, 2012 [15] (Table 3). Data based on 2011 socioeconomic survey-IBOPE (Brazilian Institute of Public Opinion and Statistics) [16].

Table 7. Comparison between children transporters and non-children transporters.

\begin{tabular}{ccc}
\hline & Children transporters (57\%) & Non-children transporters (31\%) \\
\hline Mean age & 37 years old & 40 years old \\
Mean level of schooling & $29 \%$ (Superior education) & $39 \%$ (Basic education) \\
Economic level & Class B (60\%) & Class C (50\%) \\
Familiar Income (US\$) & about 2.150 & about 1.620 \\
Region & metropolitan area & Non-metropolitan area \\
\hline
\end{tabular}

a: Economic Classification: Criteria Brazil of Economic Classification from ABEP-Brazilian Association of Research Companies, 2012 [15] (Table 3). Data based on 2011 socioeconomic survey-IBOPE (Brazilian Institute of Public Opinion and Statistics) [16].

using of the equipment is more significant among children aged between 8 and 10 years.

In most cases the child safety seat is installed in the middle seat back, in other situations, child is not a transporter with safety seat, aside of the driver (Figure 3). 


\section{Discussion}

The results show that the use of the children safety seat has grown up since the entry into force of the law, but it still reveals differences of using of the device that is influenced by some important variables that must be considered. Despite their effectiveness in reducing injury in motor vehicle collisions, the law enforcement is a barrier for the coercion of the legislation on the car safety seat.

A previous study conducted by Criança Segura-Safe Kids Brazil in 2010 showed that before the law only $32 \%$ of parents transported their children with safety devices [1]. A preliminary assessment of the impact of the children safety seat law on children under 10 years old was prepared by the Institute of Applied Economic Research (IPEA) [17] from September 2009 until August 31, 2010. Five years before the entry into force of the law, it had been experienced a gradual growth of child deaths during transport. Under the law, there was a decrease of 15\%, between September 2010 and August 2011, compared to the average of the previous five years (IPEA) [17]. Despite of this reduction, this preliminary evaluation of the impact about the restraining on child deaths by car accidents in Brazil (September, 2005 and August, 2011) showed that the mortality reduction was not statistically significant [18].

In Brazil, there is no data that shows the percentage of children that was using or not using the safety seat device in an accident followed by death, but the present research can show a general scenario of the use/non-use of the safety seat device and analyze its effects on the mortality rate.

Despite of this great achievement, in general, $57 \%$ of the adults transport children in the device, in Brazil. In China, where there is no child safety seat law, 64.8\% of adult use a safety restraint for their children [19]. In Canada, Snowdon et al. (2009) [20] conducted the first national study using direct observation to determine the effect of legislation on booster seat use. Provinces with legislation had higher booster seat use, but overall rates were still disappointingly low. Authors concluded that the ongoing surveillance of child safety seat use and evaluation of effective adjuncts to legislation are required in order to see collision-related child deaths and injuries drop in the future.

Car safety seat laws in the United States have been found to be effective; children between the ages of 4 and 7 in states with seat laws were 39\% more likely to be correctly restrained than those in other states [21]. In the present study, the law enforcement is the main reason that would influence a non-user of the safety device to use it, followed by the possibility of an accident. This shows the prevention culture in the country in weak, as well as people being conscious of the importance of the correct use of the safety device. In California, USA, in 2000, $47 \%$ of occupant fatalities among children under 5 years of age were unrestrained children [22]. In Brazil, between September 2005 and August 2011, the frequency of deaths of children under ten years due to transport accidents was $40.2 \%$ [18], but this data is not disclosed in public campaigns and educational measures.

In Brazil, the entry into force of the seat law was in 2010 and two years later we could have an overview of the use/non-use and the reasons for that. In such a diversified country under geography, social and economic disparities, the profiles of both groups (transporters and non-transporters) are different. Transporters have more favorable conditions than the general population (Table 4) and than non-transporters (Table 5). It shows that education, income, age, participation in the labor market, gender and region of origin are influent variables.

Education level and better comprehension of the necessity of the car safety seat may be important reasons for transporters. Higher income and the access to the device and other resources are important factors that influence the use of the children seat. The younger age is associated with transporters, and maybe, in this case, older adults are more resistant to accept new changes, like the seat safety law. The participation in the labor market gives more benefits to the employee compared to workers in the informal economy, without labor benefits. The participation of the children transporters in the labor market is more expressive, with greater presence of employees and entrepreneurs among the population and greater proportion in economically active population, particularly those who take part in the formal labor market, which reveals a strong correlation with car ownership and greater economic conditions.

The region of origin is an important variable, as showed in Figure 1, non-metropolitan areas concentrate lower rates of using of the device and are located, mainly, in Northeast region.

This data is consistent to the study of the National Highway Traffic Safety Administration (NHTSA) [23] that shows a low use of safety device by non-metropolitan areas and the influence of the urbanization [23]. Compared to the result of the present study and previous research information [24], we observe that non-metropolitan areas carry low education rates and socioeconomic characteristics that reflect on the safety care as showed in the 


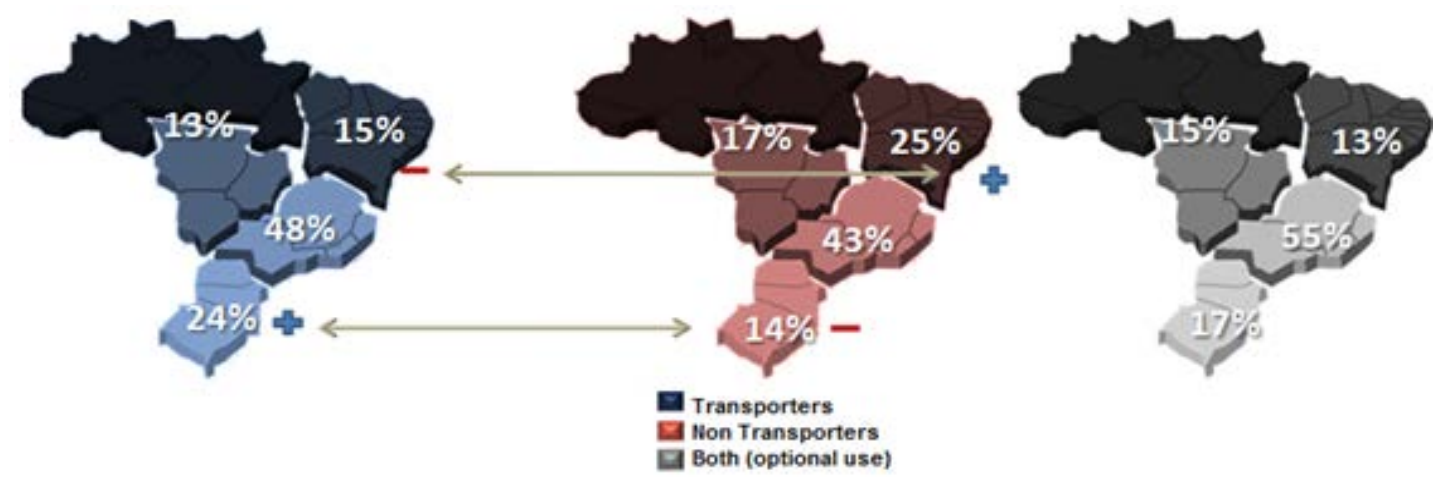

Figure 1. Profile of adults who transport children (in seat/don’t transport/both (optional)) in percentage according to region.

results.

The proportion of man is greater and they are younger when compared to the adult Brazilian population. Those that transport children up to 10 years old in cars present greater education level compared to the Brazilian population in general (Table 6). A study conducted by Lotem et al. (2006) [25] showed a telephone survey about knowledge on car safety for children that concluded stating the poor knowledge about car safety and inappropriate behavior correlated to poverty and parental level of education.

Once purchasing the car safety seat for children, the majority of adults carrying children declare that always does, every day, in every situation. The everyday use of the equipment increases according to the economic level and is most significant among people who have family income above 3 minimum wages.

Besides the law supervision, other important factors that influence the non-use of a safety seat were the physical size of the child and the small size of the seat followed by the short way route and high price of the device. Like in a Chinese study [19], in the present research the economic factor was not the first reason; the main ones express the difficult access and the lack of information. People don't have information about the variety of safe seat sizes and where they can find it. In the same context, people don't believe that traffic accidents occur in cities, reserving the use of safety seat only in highways and long routes.

In general, there is an overall low proportion of U.S. child passengers using the age-appropriate restraint and many are placed at risk by sitting in the front seat [26]. Macy and Freed (2012) [26] observed the restraint use for 21,476 children aged $<13$ years. A decline in child safety seat use and increase in being unrestrained were observed with increasing child age. In multivariate analyses, race/ethnicity, unrestrained drivers, and sitting in the front seat were associated with lower odds of child safety seat use among children aged $<8$ years. Older child age was associated with sitting in the front seat and being unrestrained. The presence of multiple child passengers was associated with lower odds of sitting in the front but higher odds of being unrestrained [26].

In Canada, Simniceanu et al. (2013) [27] concluded that the legislation has an impact on restraint use. Despite the increased number of parents that carry children in these devices, the use rates in the population studied remained low. In provinces with the after 2006, 84\% of children were restrained compared to $94.9 \%$ in provinces where the law was implemented before 2006 and 81.8\% in provinces without legislation [27].

According a survey developed by Agran, Anderson \& Winn (2005) [28] three months after payment of the fine, with in-home interviews conducted with 139 parents who had been cited for violation of the California CPS Law and whose children were aged 12 to 47 months and weighed 20 to 40 pounds, in this largely low-income Latino population of violators, self-report of "always using a child safety seat" when transporting their child was low (59\%). Child safety seat non-use was related to hassles that are associated with child behaviors and vehicle crowding/inconvenience. The child safety seat Hassles Scale used in this study documented barriers and difficulties with the use of a child safety seat in a high-risk population for non-use. These concepts can be explored by clinicians and others who work to increase consistent child safety seat use [28].

Apsler et al. (2003) [29] observed that providing free seats accompanied by training may be sufficient without the need for additional intervention to booster seat usage among low income families [30]. In this study, parents who participated in an educational training received free seats. Pre-test observations of 1854 - 8 years old found $56 \%$ riding unrestrained and fewer than 3\% riding in booster seats. After the intervention, observation of 146 
children found the number riding in booster seats increased to $38 \%$ and the number observed without restraints decreased to 26\%. Most booster seat use occurred with 4 and 5 year olds. No 7 or 8 year olds rode in booster seats. Changing center policies to recommend compliance with state restraint laws and an offer of financial incentives appeared to have no additional impact.

In a review about this practice Ehiri et al. (2006) [30] founded 1350 potential studies. Of these, five studies involving 3070 individuals met the inclusion criteria. Interventions were generally effective in increasing booster seat use among children aged 4 to 8 years. Education paired with incentive or distribution programs produced more consistent results than education-only interventions that targeted parents, children, or both. The review concluded that incentives or distribution of free booster seats combined with education increase the use of booster seats [30].

The use of the car safety seat for transporting children is more significant in the South region (24\% use and $14 \%$ don't use), while the non-using transporters are more frequent in the Northeast (25\% use and $15 \%$ don't use) and in non-metropolitan areas (69\% use and 53\% don't use).

The continued use of the equipment is strongest in the South and in Metropolitan areas, while the use on roads is more significant among those who live in the countryside and in the Southeast and Northeast. A group of respondents who have both habits, to carry and not carry children on the car safety seat (13\%) was identified (Figure 1).

In Brazil, the metropolitan region of the South of the country was the region where the use of the car safety seat was more common, mainly in children until 5 years old and for security reasons. In South, $70 \%$ transport only 1 child, while in North/Midwest $44 \%$ transport from 2 to 3 children.

In the South, the group that use car safety seat has greater awareness, mainly to children between 8 - 10 years old, and is composed by younger people, with more years of study and greater income, compared with the group that doesn't use the car safety seat.

In non-metropolitan areas, such as the Northeast of the country, a combination of factors were observed: lack of information concerning age limits and different sizes of car safety seats, older children, security and the use of the device during short paths, as well as the deficient fiscalization, resulting in greater non-use in children aged between 8 and 10 years old.

This can be explained by the law that obligates the use of the device for children until 7 years old, and due to the physical size of children above 8 years old, that difficult the use too. In this reality, more supervision of the law adherence or the threat of an accident are the motivator facts for the using of the car safety seat for people that in this region are, generally, older, with less years of study and less income, compared with the group that use the car safety seat.

Results showed that security is the reason for $94 \%$ of the transporters to carry children on car safety seats. For $37 \%$, the law/obligation is the main reason. The comfort of the children is the main reason for $13 \%$ of the people, and $3 \%$ carry children on car safety seat because this device does not permit disturbing the attention of the driver.

Among those that don't carry children in car safety seat, the main reason are related to the occurrence of a future accident, increased supervision, if children were smaller and long travels (Figure 2).

Among Brazilians that transport children up to 10 years in cars, the majority declare that they accommodates kids in proper devices (57\%), three out of ten transporters do not use this equipment (31\%) and 13\% claim to have both habits (carry the children in the seat and without seat) Figure 1.

Most children transported without car safety seat stay in the middle back seat or in the back seat, without fixed place (Figure 3). Among children aged between 8 - 10 years old who are placed on car safety seats, there is a greater preference for occupying the back seat on the left side or sit in the front seat beside the driver, while that, among the smaller children there is preference for the back seat on the right side. This preference for the middle seat back may be related to the possibility to supervise the children, even that this position is not the most indicated in case of crash.

Pan et al. (2012) [31] concluded that in China, child's age, parental license status and mothers' tertiary education were associated with how children in China are seated, and only parental license status was associated with whether children used restraints in cars. The use of safety seats in the population of this study was $39.1 \%$ and the author explain that this number could be attributed in part to the lack of comprehensive strategies such as widespread child restraint education campaigns, police enforcement targeting restraint use and compulsory child restraint use legislation [31]. 


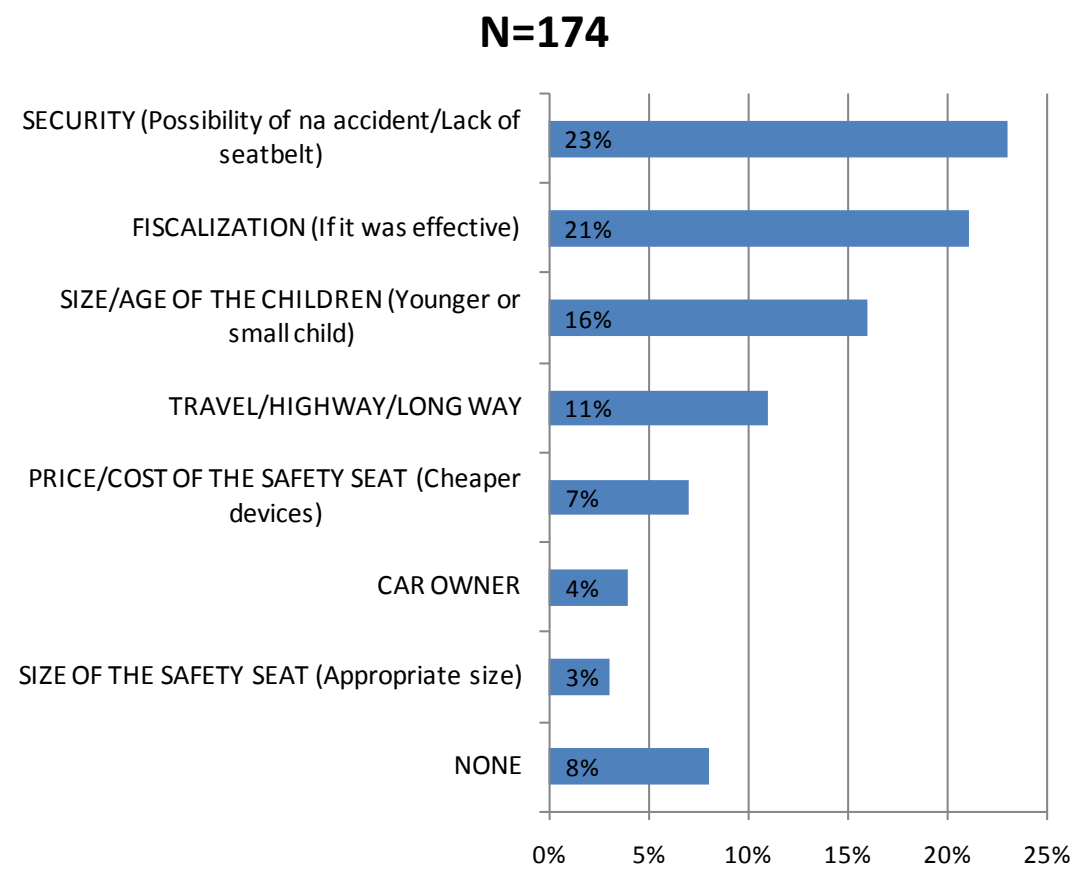

Figure 2. Reasons that influence the use of the safety seat (among those that don't carry children in safety seats) in percentage.
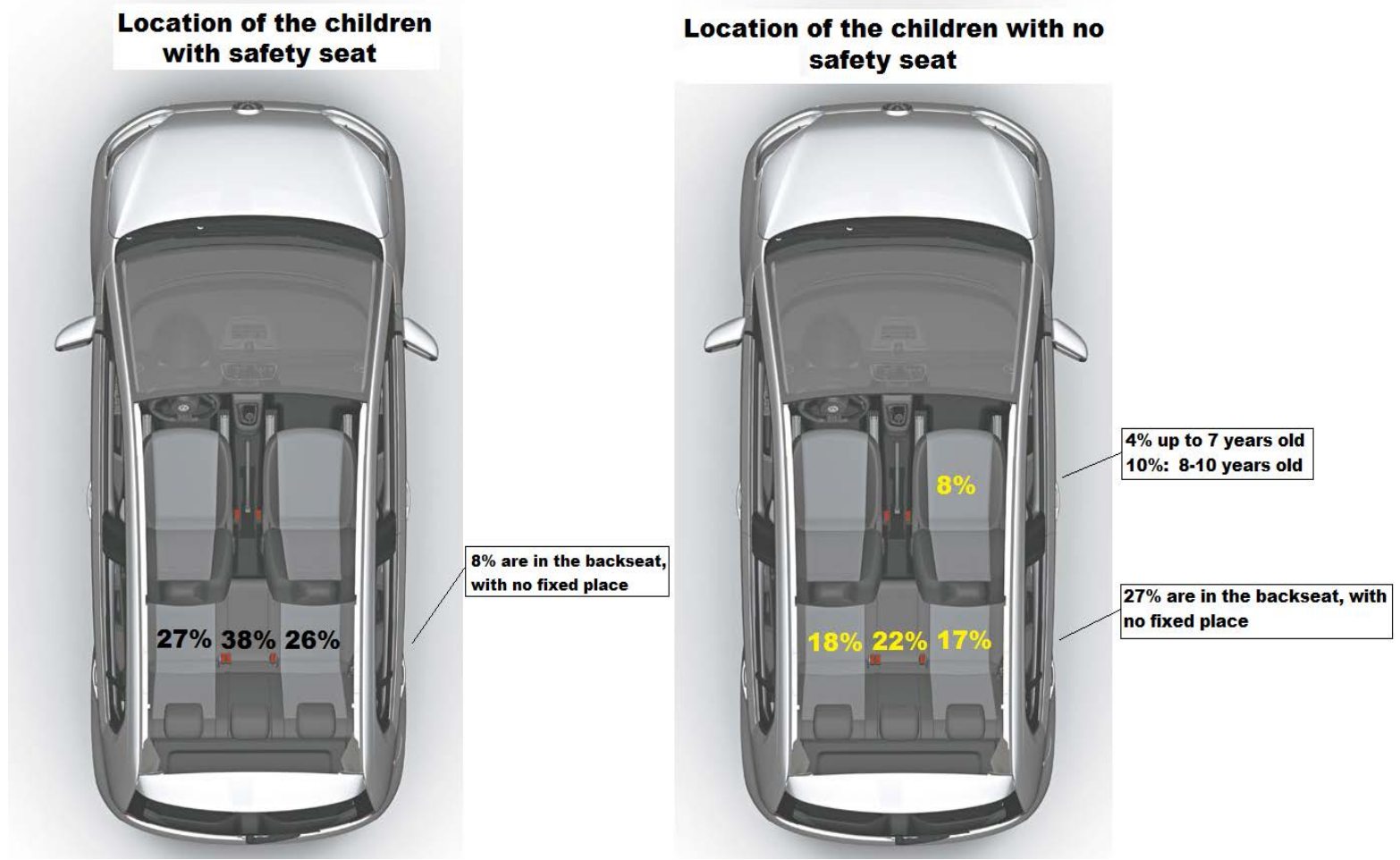

Figure 3. Profile of the location of the carried child/not carried child in car safety seats.

\section{Conclusion}

In conclusion, although there is a law that regulates child safe transportation with proper devices in Brazil, there 
is need to improve information and fiscalization in a country where there is no prevention culture and in which people still don't see prevention as best care for their children.

\section{References}

[1] Criança Segura—Safe Kids Brazil (2013) Accessed on 17/08/2013. www.criancasegura.org.br

[2] De Campos Vieira Abib, S. (2013) Pediatric Non Intentional Injuries: Prospective Study in Five Hospitals of São Paulo City, Brazil—Social, Educational Factors, Severity and Prevention—São Paulo 2013. Full Professor Thesis Presented at the Federal University of São Paulo-Paulista School of Medicine.

[3] Arbogast, K.B., Jermakian, J.S., Kallan, M.J. and Durbin, D.R. (2009) Effectiveness of Belt Positioning Booster Seats: an Updated Assessment. Pediatrics, 124, 1281-1286 http://dx.doi.org/10.1542/peds.2009-0908

[4] Zaloshnja, E., Miller, T.R. and Hendrie, D. (2007) Effectiveness of Child Safety Seats vs. Safety Belts for Children Aged 2 to 3 Years. Archives of Pediatrics \& Adolescent Medicine, 161, 65-68. http://dx.doi.org/10.1001/archpedi.161.1.65

[5] Elliott, M.R., Kallan, M.J., Durbin, D.R. and Winston, F.K. (2006) Effectiveness of Child Safety Seats vs. Seat Belts in Reducing Risk for Death in Children in Passenger Vehicle Crashes. Archives of pediatrics \& Adolescent Medicine, 160, 617-621. http://dx.doi.org/10.1001/archpedi.160.6.617

[6] Durbin, D.R., Elliott, M.R. and Winston, F.K. (2003) Belt-Positioning Booster Seats and Reduction in Risk of Injury among Children in Vehicle Crashes. JAMA: The journal of the American Medical Association, 289, 2835-2840. http://dx.doi.org/10.1001/jama.289.21.2835

[7] Durbin, D.R., Chen, I., Smith, R., Elliott, M.R. and Winston, F.K. (2005) Effects of Seating Position and Appropriate Restraint Use on the Risk of Injury to Children in Motor Vehicle Crashes. Pediatrics, 115, e305-e309. http://dx.doi.org/10.1542/peds.2004-1522

[8] Devolin, M., Phelps, D., Duhaney, T., Benzies, K., Hildebrandt, C., Rikhy, S. and Churchill, J. (2013) Information and Support Needs among Parents of Young Children in a Region of Canada: A Cross-Sectional Survey. Public Health Nursing, 30, 193-201. http://dx.doi.org/10.1111/phn.12002

[9] Oliveira, S.R., Carvalho, M.D., Santana, R.G., Camargo, G.C., Lüders, L. and Franzin, S. (2009) Child Safety Restraint Use among Children Attending Day Care Centers. Revista de Saúde Pública, 43, 761-767. http://dx.doi.org/10.1590/S0034-89102009005000052

[10] Oliveira, S.R., Leone, C., Carvalho, M.D., Santana, R.G., Luders, L.E. and Oliveira, F.C. (2012) Child Safety Seat Usage Errors in Under-4s. Jornal de Pediatria, 88, 297-302.

[11] Abib, S.C.V., Françoia, A., O’Reilly, L., NGO Criança Segura—Safe Kids Brazil 2010 (2010) Accidents Involving Children: Perception and Behavior of Brazilian Mothers. Accessed on 2/7/13. www.criancasegura.org.br

[12] Margolis, L.H., Bracken, J. and Stewart, J.R. (1996) Effects of North Carolina's Mandatory Safety Belt Law on Children. Injury Prevention, 2, 32-35. http://dx.doi.org/10.1136/ip.2.1.32

[13] National Traffic Council (CONTRAN) (2013) Provides for the Transportation of Children under 10 and Use of Restraint Device for Transporting Children in Vehicles. Resolution No. 277 of May 28, 2008, Accessed: 08/06/2013. http://www.denatran.gov.br/download/Resolucoes/RESOLUCAO CONTRAN 277.pdf .

[14] Brazilian Institute of Geography and Statistics (IBGE) (2013) Accessed on 08/06/2013. www.ibge.gov.br

[15] ABEP_Brazilian Association of Research Companies (2012) Accessed on 15/08/2013. www.abep.org

[16] The Brazilian Institute of Public Opinion and Statistics (IBOPE) (2013) Data Based on 2011 Socioeconomic Survey. Accessed on 21/06/2013. www.ibope.com.br

[17] Institute of Applied Economic Research (IPEA) (2013) Accessed in 12/06/2013. http://www.ipeadata.gov.br

[18] Garcia, L.P., Freitas, L.R.S. and Duarte, E.C. (2012) Preliminary Impact Evaluation of Mandatory Restraining on Child Deaths by Car Accidents in Brazil: A Time-Series Study (2005-2011). Revista Brasileira de Ortopedia (English Edition), 21, 367-374.

[19] Purc-Stephenson, R.J., Ren, J. and Snowdon, A.W. (2010) An Exploratory Study of Parents' Use and Knowledge of car Safety Seats in Beijing, China. International Journal of Injury Control and Safety Promotion, 17, 231-238. http://dx.doi.org/10.1080/17457300.2010.487155

[20] Snowdon, A., Rothman, L., Slater, M., Kolga, C., Hussein, A., Boase, P. and Howard, A. (2009) A Comparison of Booster Seat Use in Canadian Provinces with and without Legislation. Injury Prevention, 15, 230-233. http://dx.doi.org/10.1136/ip.2008.020537

[21] Winston, F.K., Kallan, M.J. and Elliott, M.R. (2007) Effect of Booster Seat Laws on Appropriate Restraint Use by Children 4 to 7 Years Old Involved in Crashes. Archives of Pediatrics Adolescent Medicine, 161, 270-275. 
http://dx.doi.org/10.1001/archpedi.161.3.270

[22] Agran, P.F., Anderson, C.L. and Winn, DG. (2004) Violators of a Child Passenger Safety Law. Pediatric, 114, 109115. http://dx.doi.org/10.1542/peds.114.1.109

[23] National Highway Traffic Safety Administration (NHTSA) (2013) Accessed on 14/06/2013. www.nhtsa.gov

[24] Galeano, P. (2011) Education in Territories of High Social Vulnerability in the Metropolis. Centre for Studies and Research in Education, Culture and Community Action (CENPEC). Accessed on 11/01/2013. http://www.acaoeducativa.org.br

[25] Lotem, M.H., Urkin, J., Findling, L.E. and Merrick, J. (2006) Parental Knowledge on car Safety for Children: An Israeli Survey. The Scientific World Journal, 6, 30-34

[26] Macy, M.L. and Freed, G.L. (2012) Child Passenger Safety Practices in the U.S. Disparities in Light of Updated Recommendations. American Journal of Preventive Medicine, 43, 272-281. http://dx.doi.org/10.1016/j.amepre.2012.05.023

[27] Simniceanu, A., Richmond, S.A., Snowdon, A., Hussein, A., Boase, P. and Howard, A. (2013) Child Restraint Use in Canadian Provinces with and without Legislation in 2010. Traffic Injury Prevention, 15, 734-737.

[28] Agran, P.F., Anderson, C. and Winn, D.G. (2006) Development of a Child Safety Seat Hassles Scale in a Largely LowIncome Latino Population. Pediatrics, 118, 2005-2211.

[29] Apsler, R., Formica, S.W., Rosenthal, A.F. and Robinson, K. (2003) Increases in Booster Seat Use among Children of Low Income Families and Variation with Age. Injury Prevention, 9, 322-325. http://dx.doi.org/10.1136/ip.9.4.322

[30] Ehiri, J.E., Ejere, H.O.D., Hazen, A.E., Emusu, D., King, W.D. and Osberg, S.J. (2006) Interventions to Increase Children's Booster Seat Use a Review. American Journal of Preventive Medicine, 31, 185-192. http://dx.doi.org/10.1016/j.amepre.2006.03.020

[31] Pan, S., Du, W., Jiang, F., Bilston, L.E., Brown, J. and Shen, X. (2012) Exploring Child Car passenger Safety Practices in China: Experience from a Parental Survey in Shanghai. Injury Prevention, 18, 133-137. http://dx.doi.org/10.1136/injuryprev-2011-040049 
Scientific Research Publishing (SCIRP) is one of the largest Open Access journal publishers. It is currently publishing more than 200 open access, online, peer-reviewed journals covering a wide range of academic disciplines. SCIRP serves the worldwide academic communities and contributes to the progress and application of science with its publication.

Other selected journals from SCIRP are listed as below. Submit your manuscript to us via either submit@scirp.org or Online Submission Portal.
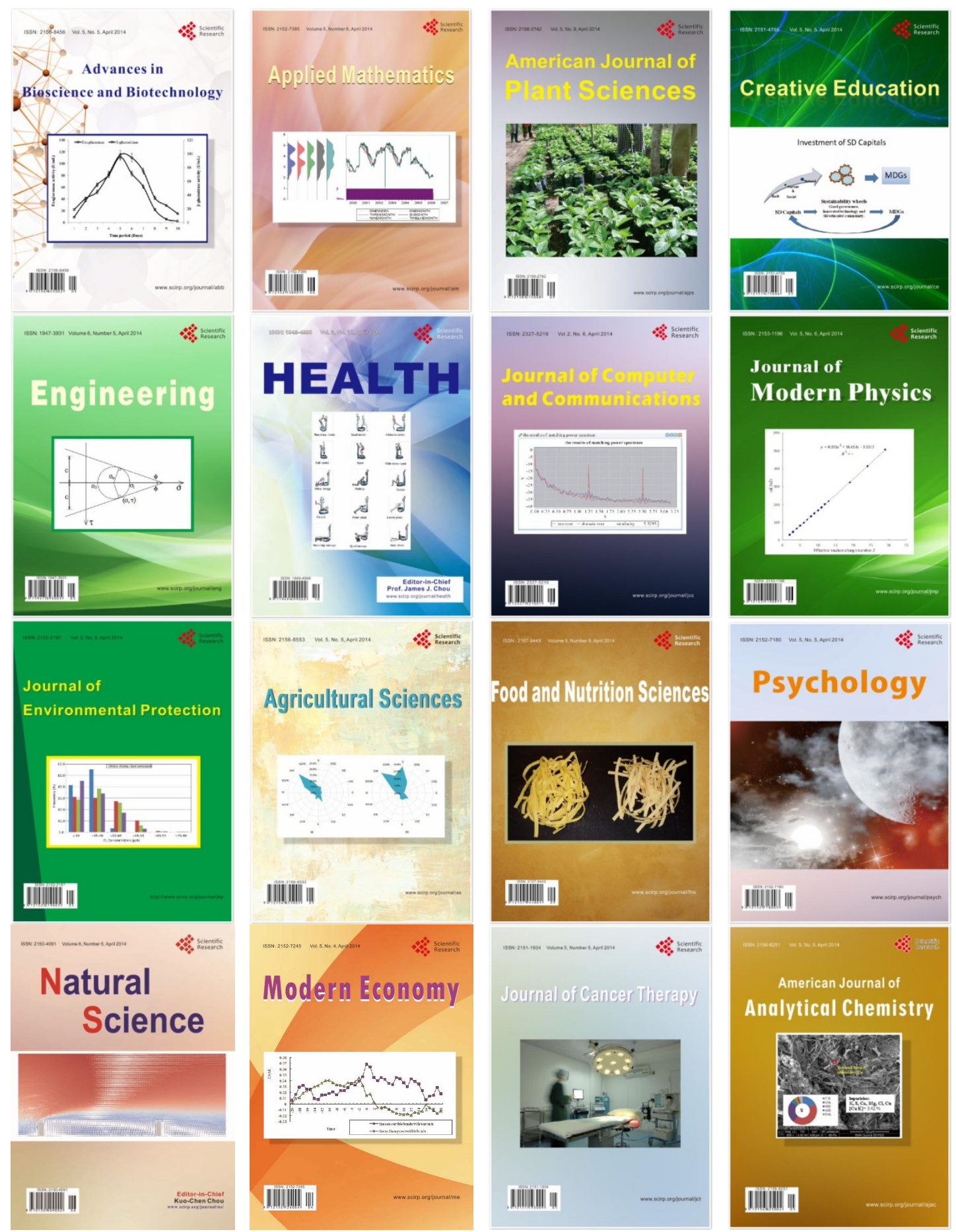